\title{
Sonographically Assessed Intra-Abdominal Fat And Cardiometabolic Risk Factors in Adolescents with Extreme Obesity
}

\author{
Anja Moss $^{a} \quad$ Kolja Sievert $^{b} \quad$ Wolfgang Siegfried $^{b} \quad$ Alena Siegfried $^{b}$ \\ Stephanie Brandt ${ }^{a}$ Wolfgang Koenig ${ }^{c}$ Martin Wabitsch ${ }^{a}$ \\ aDivision of Paediatric Endocrinology and Diabetes, Department of Paediatrics and \\ Adolescent Medicine, Ulm University, Ulm, Germany; ${ }^{b}$ Obesity Rehabilitation Centre \\ INSULA, Berchtesgaden, Germany; ' ${ }^{c}$ Department of Internal Medicine II, Ulm University, \\ Ulm, Germany
}

\section{Key Words}

Extreme obesity $\cdot$ Adolescents $\cdot$ Intra-abdominal fat $\cdot$ Cardiometabolic risk factors

\begin{abstract}
Objective: The metabolic and cardiovascular risk of obesity is predominantly defined through the amount of intra-abdominal fat (IAF). Regarding this risk and the benefits of weight reduction gender-specific differences have been described. The aim of this study was to examine the gender-specific relationship between IAF assessed via ultrasound and the cardiometabolic risk profile in extremely obese adolescents before and after weight loss. Methods: In 107 consecutively admitted adolescents ( $n=59$ girls, mean age $15.4 \pm 2.6$ years boys and 15.1 \pm 2.1 years girls, mean BMI z-score $3.2 \pm 0.6$ boys and $3.5 \pm 0.6$ girls) anthropometric and fasting laboratory chemical parameters were measured before and after an in-patient long-term therapy (mean durance $5.6 \pm 2.3$ months). IAF was determined by measuring the intra-abdominal depth (IAD) via ultrasound. Results: IAD was higher in boys as compared to girls (58.0 \pm $22.4 \mathrm{~mm}$ vs. $51.3 \pm 16.0 \mathrm{~mm}$ ). IAD values were positively associated with BMI-z scores, waist circumferences, HOMA-IR and serum levels of $\gamma$ GT, hs-CRP and IL- 6 in both genders. In boys, but not in girls, IAD was significantly correlated with systolic and diastolic blood pressure, serum levels of triglycerides, ALT as well as adiponectin and HDL-cholesterol. After a marked mean weight loss of $-27.1 \pm 16.2 \mathrm{~kg}(-20.1 \pm 7.9 \%)$ in boys and of $-20.5 \pm 11.5 \mathrm{~kg}(-17.3 \pm 7.1 \%)$ in girls, IAD decreased by $-20.7 \pm 16.2 \mathrm{~mm}(--32.4 \pm 16.9 \%)$ in boys and by $-18.4 \pm 12,7 \mathrm{~mm}$ $(-34.3 \pm 18.4 \%)$ in girls, resulting in more pronounced ameliorations of cardiovascular risk factors in boys than in girls. Conclusions: The present study indicates that IAF assessed by ultrasound is a good indicator for the cardiometabolic risk factor profile in extremely obese adolescents. Associations between IAF and risk factors are more pronounced in boys than in girls.

(C) 2016 The Author(s)

Published by S. Karger GmbH, Freiburg
\end{abstract}


Moss et al.: Sonographically Assessed Intra-Abdominal Fat And Cardiometabolic Risk Factors in Adolescents with Extreme Obesity

\section{Introduction}

The prevalence of childhood obesity increased markedly in the past 30 years, but new reports show a stabilisation or even a decline in recent years in developed countries [1]. However, prevalence rates remain on a high level. Additionally, a worrisome trend emerged in the form of extreme obesity as the fastest growing sub-category of obesity in children and adolescents [2-4].

Even in childhood and adolescence, obesity is associated with a high prevalence of morbidity and mortality and has a major impact on health status in adulthood [5, 6]. Children and adolescents with extreme obesity display a separate risk group which show a more adverse cardiometabolic risk factor profile compared to obese or overweight youth [7-12]. They have a high risk for early onset of obesity-associated mental and somatic co-morbidity, such as disturbed glucose tolerance, insulin resistance, hyperinsulinaemia, and hyperglycaemia, thus leading to an increased risk for diabetes [13-17] as well as lipid abnormalities and hypertension [18-24]. Furthermore, being extremely obese in childhood displays a much stronger risk factor for being obese in adulthood [25].

The distribution of body fatseems to be more important for the development of co-morbidities than overall weight or fat mass [26-29]. Especially abdominal obesity is related to cardiovascular risk factors such as hyperinsulinaemia [30,31], dyslipidaemia [19, 32, 33] and hypertension [20,23,34], already in children and adolescents. Additional distinction between intra-abdominal fat (IAF) or visceral adipose tissue (VAT) and subcutaneous fat reveals a higher morbidity associated with the former in adults [35-37]. Matching this, studies in children showed that fasting insulin and lipid levels are more strongly influenced by visceral than by subcutaneous fat [38-40].

Direct imaging of IAF has proven to be a better predictor of metabolic risk factors than waist circumference [41-43]. Therefore, assessment of IAF might provide an adequate measure for the estimation of metabolic risk factor profile. The gold standard for assessment of IAF is CT or MRI measurement, even in children [44-46]. However, their disadvantages, such as high costs, radiation exposure (for CT) and limited availability, render them impractical for population studies. A relatively new methodological approach is the assessment of IAF by ultrasound sonography. Studies in adults and children have shown a very good correlation of intraabdominal fat measured by sonography and by CT or MRI [47-50].

The aim of this study was to examine cardiometabolic risk factors of severely obese male and female adolescents in relation to IAF assessed by ultrasound before intervention (baseline) as well as to investigate changes in IAF and in cardiometabolic risk factors after a long-term in-patient treatment programme resulting in marked weight loss. We further wanted to elucidate gender-specific differences in the relationship between IAF and cardiometabolic risk factors.

\section{Material and Methods}

\section{Study Population}

A total of 107 extremely obese adolescents (59 girls) aged 12-23 (15.3 \pm 2.3 ) years with a mean BMI of $41.3 \pm 9.3 \mathrm{~kg} / \mathrm{m}^{2}$ and a mean BMI-z score of $3.5 \pm 0.6$ (girls) or $3.2 \pm 0.6$ (boys) were consecutively recruited according to their admission within 18 months from the INSULA obesity rehabilitation centre, Bischofswiesen, Germany.

Written informed consent from parents and written assent from adolescents were obtained. The ethics committee of the University of Ulm approved all study proceedings. The trial protocol meets the standards of the Declaration of Helsinki in its revised version of 1975 and its amendments of 1983, 1989, and 1996. 
Moss et al.: Sonographically Assessed Intra-Abdominal Fat And Cardiometabolic Risk Factors in Adolescents with Extreme Obesity

\section{Anthropometric and Metabolic Measurements}

At study entry (baseline t0) and study exit (end of therapy t1) weight and height were determined in lightly apparel with calibrated scales to the nearest $0.1 \mathrm{~kg}$ (Soehnle S20/2760; Leifheit AG, Nassau, Germany) and 0.1 centimetres (Seca Mod. 220; Seca GmbH \& Co. KG, Hamburg, Germany), respectively. The BMI calculated from weight (kilograms) / height (meters) ${ }^{2}$ was used to estimate the degree of obesity. Extreme obesity has been defined as BMI > 99.5th age- and gender-specific percentile. Standard deviation scores of BMI (BMI-z score) were calculated based on the LMS method. BMI reference data for German children were used [51]. Waist circumferences were measured midway between the lower rib margin and the iliac crest with a non-elastic measuring tape. Systolic and diastolic blood pressures were measured twice at the left arm after a 10-min rest in a seated position using a calibrated Omron S2 (OMRON Medizintechnik Handelsgesellschaft $\mathrm{mbH}$, Mannheim, Germany).

Baseline and follow-up blood samples were obtained after a 12-hour overnight fast, followed by a standard oral glucose tolerance test (oGTT). Samples were obtained by venous puncture and processed shortly after withdrawal. All measurements were carried out by two trained nurses.

\section{Biochemical Analyses}

Blood glucose from oGTT was measured in a fluoride monovette with Cobas Integra 800 (Roche, Mannheim, Germany). Triglycerides (TG), cholesterol, LDL- and HDL-cholesterol, AST, ALT and $\gamma$ GT were photometrically measured with Cobas 6000 (Roche, Mannheim, Germany). Serum adiponectin was measured using an ELISA (Mercodia, Uppsala, Sweden), serum IL-6 was measured with high sensitive ELISA (R\&D Systems, Minneapolis, IN, USA), serum hs-CRP was measured with nephelometry (Siemens, Eschborn, Germany), serum C-peptide and insulin were measured with ELISA (AMP, Obrigheim, Germany). Inter- and intra-assay coefficients of variation did not exceed $10 \%$. Homeostasis model assessment for insulin resistance index (HOMA-IR) was calculated according to the following formula: resistance $(\mathrm{HOMA})=$ (insulin $(\mu \mathrm{U} / \mathrm{ml}) \times$ glucose $(\mathrm{mg} / \mathrm{dl})) / 405$.

\section{Ultrasound Studies}

Ultrasound examinations were performed by a single examiner using a Siemens Sono G 40 (Siemens, Munich, Germany) equipped with a $3.5 \mathrm{MHz}$ curvel-array probe and an $8 \mathrm{MHz}$ linear-array probe. Scans were performed in supine position after an overnight fasting period of patients after inspiration and then bated breath, applying minimal pressure.

The visceral fat mass was estimated by measuring the intra-abdominal depth (IAD), the distance between the internal face of the Musculus rectus abdominis and the anterior wall of the aorta along the Linea alba at the height of the branching of the Arteria mesenterica superior, as described earlier [52]. IAD has been reported to have strong correlations with visceral fat area determined by CT [47, 48, 50, 53]. After sonographic measurements a second independent examiner sized the images three times. The mean value was taken for analysis. As recently reported, these sonographic methods have high validity, good reproducibility and low intra-observer variation [54]. With regard to baseline IAD (mm) and relative changes in IAD (\%), three groups were defined for analysing metabolic risk factor profile: group 1: $<25$ th percentile, group 2 : $>25$ th to $<75$ th percentile, and group 3: $>75$ th for percentile of baseline IAD ( $\mathrm{mm}$ ) and of $\triangle \mathrm{IAD}(\%)$.

\section{Treatment Programme}

The severely obese adolescents were enrolled in an in-patient weight reduction programme conducted by the Obesity Rehabilitation Centre INSULA (Berchtesgaden, Germany). Therapeutic foreground is solutionoriented psychotherapy with behaviour therapy, exercise training (ET), dietetic treatment as well as an extensive clinical diagnosis and therapy of obesity-associated diseases. Special goals are the long-term modification of physical activity, leisure time and dietary behaviour. An adventure educational approach and discussion rounds with former patients are used. The usual stay in the INSULA centre is 6 months. Within changes of eating behaviour approximately 1,700 kcal were delivered daily. Besides background information 
Moss et al.: Sonographically Assessed Intra-Abdominal Fat And Cardiometabolic Risk Factors in Adolescents with Extreme Obesity

about healthy foods, the patients participate in practical courses in the in-house teaching kitchen. The ET comprises a regularly strength and endurance training (at least 4 times per week) for the whole therapy duration. Teaching of parents was done by the staff within all therapeutically areas to prevent relapse into old behaviour patterns (www.dw-hohenbrunn.de/insula/adipositas-rehazentrum).

\section{Statistical Methods}

For statistical analyses all available data (anthropometric and clinical data) of the participants of the INSULA trial were included. For some subjects, levels of fasting blood parameters are missing (TG $\mathrm{n}=10$; cholesterol $n=10$; LDL-cholesterol $n=11$; HDL-cholesterol $n=11$; AST $n=7$; ALT $n=7$; $\gamma$ GT $n=7$; adiponectin $n=7$, IL-6 $n=7$, CRP $n=7$, HOMA $n=9$ ). Measurement of systolic and diastolic blood pressure is missing for 1 patient. Measurement of waist circumference is missing for 1 patient.

The descriptive statistics summarised the characteristics of the study population. Data are presented as mean and standard deviation for continuous variables. Relative changes were calculated as change in variable divided by baseline variable $\times 100$. Correlations between IAD levels at baseline / $\Delta$ levels of IAD and cardiometabolic risk factor concentrations at baseline / $\Delta$ levels of cardiometabolic risk factor concentrations were investigated by Spearman's correlations (Spearman's rho). Crude and partially adjusted correlation analyses were conducted. Because gender differences in IAD have been reported in the literature [55-57], all analyses were separately performed for boys and girls. To take into account that the age at baseline and the therapy duration could be different between the participants, these factors were considered as further potential confounders.

A one-way ANOVA was used for between-group comparisons (low, middle and high $\Delta$ levels of IAD) on baseline and $\Delta$ levels of cardiometabolic risk factor concentrations. Bonferroni post-hoc tests were used to carry out pair-wise comparisons.

All analyses were carried out with the Statistical Analyses System (SAS) version 9.3 (SAS Institute Inc., Cary, NC, USA). We conducted exploratory analyses without formal hypothesis testing and correction for multiple comparisons. Statistical significance was interfered at two-tailed $\mathrm{p}<0.05$.

\section{Results}

The 107 adolescents ( $n=59$ girls) had a mean age of $15.4 \pm 2.6$ (boys) and $15.1 \pm 2.1$ (girls) years. Mean treatment duration was $5.6 \pm 2.3$ months. Anthropometric and metabolic characteristics of the study population at baseline are summarised in table $1 \mathrm{a}$.

\section{Baseline, Cross-Sectional Analysis}

As shown in table $1 \mathrm{a}$, male and female study participants were markedly obese with a mean BMI z-score of $3.2 \pm 0.6$ in boys and $3.5 \pm 0.6$ in girls $(\mathrm{p}<0.05)$ before start of the in-patient treatment programme. Despite the lower baseline BMI z-score, baseline mean IAD was higher in boys as compared to girls (58.0 $\pm 22.4 \mathrm{~mm}$ vs. $51.3 \pm 16.0 \mathrm{~mm}$ ) with concurrently higher mean waist circumference (127.7 $\pm 20.6 \mathrm{~cm}$ (boys) vs. $124.1 \pm 16.5 \mathrm{~cm}$ (girls)). In addition, boys had markedly higher levels of liver enzymes than girls.

\section{Cardiometabolic Risk Factors in Relation to Baseline IAD}

As shown in table 2, measurements of IAD at baseline were significantly $(\mathrm{p}<0.05)$ associated with higher BMI z-scores, waist circumferences, IL- 6 in both boys and girls as well as with HOMA-IR (girls $\mathrm{p}<0.05$ ) and serum levels of hs-CRP (boys $\mathrm{p}<0.01$ ). 
Moss et al.: Sonographically Assessed Intra-Abdominal Fat And Cardiometabolic Risk Factors in Adolescents with Extreme Obesity

Table 1. Baseline patient characteristics

\begin{tabular}{|c|c|c|c|c|c|}
\hline & \multicolumn{2}{|c|}{ Girls $(n=59)$} & \multicolumn{2}{|c|}{ Boys $(n=48)$} & \multirow[t]{2}{*}{$\mathrm{p}$ values } \\
\hline & mean & SD & mean & SD & \\
\hline Age, years & 15.1 & 2.08 & 15.4 & 2.61 & 0.6303 \\
\hline BMI-z score & 3.5 & 0.61 & 3.2 & 0.56 & 0.0087 \\
\hline Waist circumference, $\mathrm{cm}$ & 124.1 & 16.45 & 127.7 & 20.59 & 0.3219 \\
\hline RR systolic, mm Hg & 125.9 & 12.10 & 126.4 & 10.91 & 0.8245 \\
\hline RR diastolic, mm Hg & 81.6 & 8.94 & 82.4 & 8.75 & 0.6431 \\
\hline $\mathrm{IAD}, \mathrm{mm}$ & 51.3 & 16.00 & 58.0 & 22.36 & 0.0862 \\
\hline $\mathrm{TG}, \mathrm{mmol} / \mathrm{l}$ & 1.3 & 0.61 & 1.3 & 0.96 & 0.9482 \\
\hline Cholesterol, mmol/l & 4.3 & 0.86 & 4.1 & 0.88 & 0.2894 \\
\hline LDL-cholesterol, mmol/l & 2.7 & 0.74 & 2.6 & 0.77 & 0.5771 \\
\hline HDL-cholesterol, mmol/l & 1.2 & 0.30 & 1.1 & 0.30 & 0.2142 \\
\hline AST, U/l & 25.2 & 10.03 & 31.8 & 14.72 & 0.0117 \\
\hline ALT, U/l & 31.7 & 20.57 & 47.3 & 37.97 & 0.0161 \\
\hline$\gamma \mathrm{GT}, \mathrm{U} / \mathrm{l}$ & 21.7 & 11.52 & 24.7 & 12.54 & 0.2102 \\
\hline Adiponectin, $\mu \mathrm{g} / \mathrm{ml}$ & 6.7 & 2.31 & 6.5 & 2.37 & 0.6545 \\
\hline IL-6, pg/ml & 3.5 & 2.35 & 3.2 & 2.05 & 0.4026 \\
\hline hs-CRP, mg/l & 5.0 & 5.11 & 4.9 & 5.05 & 0.9680 \\
\hline HOMA-IR & 5.5 & 3.08 & 4.8 & 2.30 & 0.1958 \\
\hline
\end{tabular}

RR = Riva Rocchi

$\mathrm{p}<0.05=$ statistically significant between girls and boys.

Initial IAD values in boys, but not in girls, were significantly associated with most of the other cardiometabolic risk factors, as there are systolic and diastolic blood pressure, serum levels of TG, ALT, $\gamma \mathrm{GT}$, as well as adiponectin and HDL-cholesterol (table 2).

Analysis of the cardiometabolic risk factors in the 3 defined groups according to initial IAD ( $<25$ th percentile, $>25$ th to $<75$ th percentile, and $>75$ th percentile of baseline IAD) showed differences of mean values between groups which were however not statistically significant (table 3). Boys with the highest baseline IAD were older than boys with lowest IAD $(16.6 \pm 3.1$ vs. $13.8 \pm 1.2$ years), whereas in girls no difference in age between these IAD groups (15.2 \pm 2.3 vs. $15.0 \pm 2.2$ years) could be seen. Patients with highest baseline IAD had the highest baseline BMI-z-scores, waist circumferences, systolic and diastolic blood pressure, HOMA-IR and IL-6 and hs-CRP levels compared to the other groups, applying for boys and girls. With regard to blood lipids, boys with highest baseline IAD showed markedly higher levels of mean TG, cholesterol, and LDL-cholesterol as well as lower levels of HDL-cholesterol compared with boys with lowest baseline IAD. This was not seen in girls. Additionally, baseline mean $\gamma$ GT levels were found to be highest in boys with the highest amount of baseline IAD. Baseline mean adiponectin levels were lower with the highest baseline IAD as compared to boys in the lower IAD groups in boys only.

\section{Longitudinal Analysis}

The mean weight loss was $-27.1 \pm 16.2 \mathrm{~kg}(-20.1 \pm 7.9 \%)$ in boys and $-20.5 \pm 11.5 \mathrm{~kg}$ $(-17.3 \pm 7.1 \%)$ in girls, reducing the mean BMI z-score by $0.8 \pm 0.3$ (boys) and $0.7 \pm 0.4$ (girls) as well as the mean waist circumference by $21.8 \mathrm{~cm} \pm 10.7$ (boys) and $17.5 \mathrm{~cm} \pm 9.4$ (girls) $(\mathrm{p}<0.05)$. As expected, the anthropometric and cardiometabolic risk factors improved significantly in both sexes during weight loss (table 1b). 


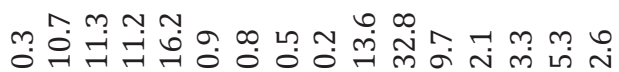

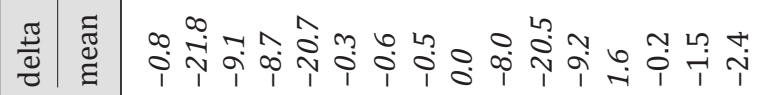

䒕

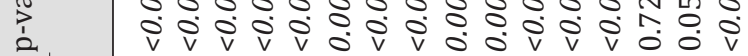

की

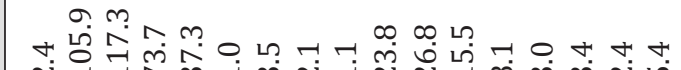

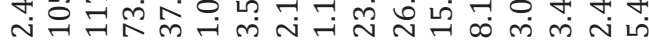

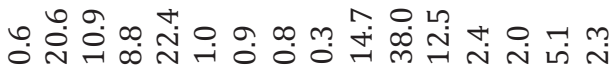



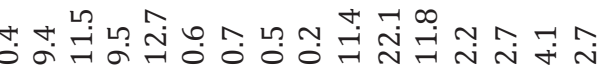

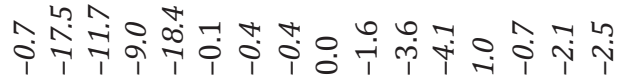

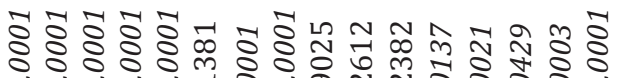
v $\begin{gathered}\dot{v} \\ 0\end{gathered}$

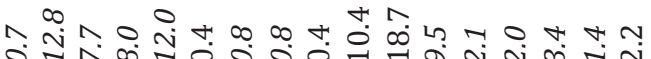

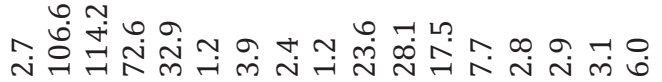

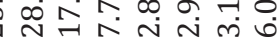

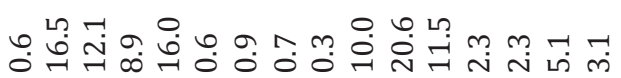

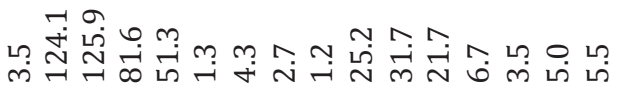

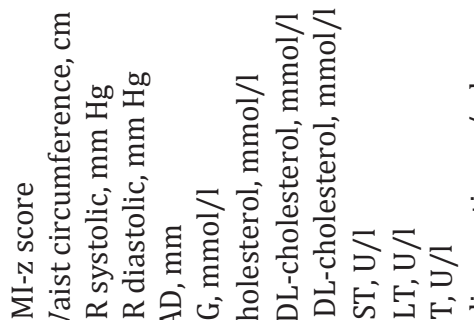

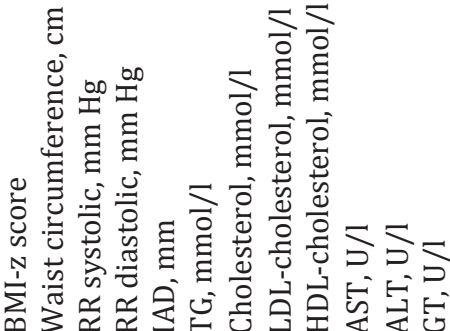
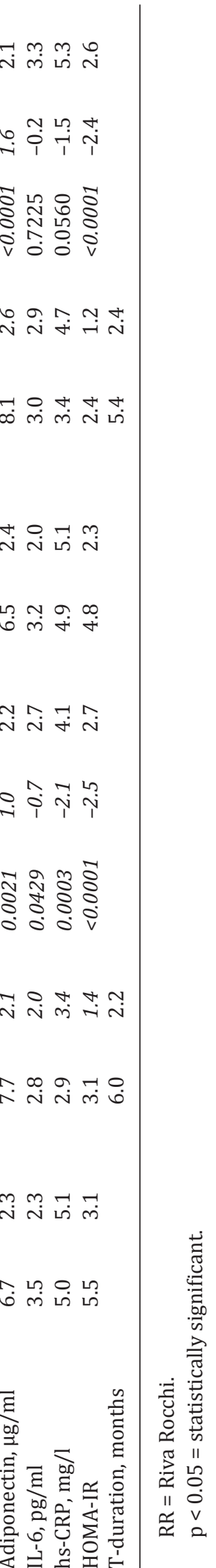
Moss et al.: Sonographically Assessed Intra-Abdominal Fat And Cardiometabolic Risk Factors in Adolescents with Extreme Obesity

Table 3. Correlations (crude and adjusted for age) between measurements of IAD and cardiometabolic risk factors in boys and girls at baseline examination

\begin{tabular}{|c|c|c|c|c|c|c|c|c|}
\hline \multirow[t]{3}{*}{ Parameter } & \multicolumn{8}{|c|}{ IAD, mm, baseline } \\
\hline & \multicolumn{4}{|c|}{ girls $(n=59)$} & \multicolumn{4}{|c|}{ boys $(n=48)$} \\
\hline & $\mathrm{r}_{\text {crude }}$ & $\mathrm{p}$ values & $\mathrm{r}_{\mathrm{adj}}{ }^{\mathrm{a}}$ & $\mathrm{p}$ values & $\mathrm{r}_{\text {crude }}$ & $\mathrm{p}$ values & $\mathrm{r}_{\mathrm{adj}}{ }^{\mathrm{a}}$ & $\mathrm{p}$ values \\
\hline BMI-z score & 0.46 & 0.0003 & & & 0.41 & 0.0048 & & \\
\hline Waist circumference, $\mathrm{cm}$ & 0.33 & 0.011 & 0.33 & 0.0111 & 0.43 & 0.0200 & 0.22 & 0.1432 \\
\hline RR systolic, mm Hg & 0.09 & 0.4955 & 0.09 & 0.4983 & 0.43 & 0.0019 & 0.28 & 0.0472 \\
\hline RR diastolic, mm Hg & 0.00 & 0.97 & 0.00 & 0.98 & 0.49 & 0.0004 & 0.33 & 0.0225 \\
\hline $\mathrm{TG}, \mathrm{mmol} / \mathrm{l}$ & 0.08 & 0.551 & 0.08 & 0.5669 & 0.29 & 0.0479 & 0.18 & 0.2483 \\
\hline Cholesterol, mmol/l & 0.09 & 0.5258 & 0.10 & 0.48 & 0.03 & 0.8359 & 0.03 & 0.8635 \\
\hline LDL-cholesterol, mmol/l & 0.02 & 0.8908 & 0.02 & 0.8981 & 0.04 & 0.7814 & 0.03 & 0.8418 \\
\hline HDL-cholesterol, mmol/l & 0.08 & 0.5919 & 0.13 & 0.3503 & -0.48 & 0.0011 & -0.36 & 0.0185 \\
\hline AST, U/l & 0.07 & 0.5908 & 0.07 & 0.6067 & 0.13 & 0.4117 & 0.05 & 0.7267 \\
\hline ALT, U/l & 0.15 & 0.2841 & 0.15 & 0.2694 & 0.35 & 0.0242 & 0.22 & 0.1547 \\
\hline$\gamma \mathrm{GT}, \mathrm{U} / \mathrm{l}$ & 0.21 & 0.1295 & 0.22 & 0.1036 & 0.34 & 0.0243 & 0.17 & 0.262 \\
\hline Adiponectin, $\mu \mathrm{g} / \mathrm{ml}$ & -0.04 & 0.754 & -0.04 & 0.7892 & -0.33 & 0.0265 & -0.23 & 0.1386 \\
\hline IL-6, pg/ml & 0.30 & 0.0277 & 0.31 & 0.0243 & 0.55 & 0.0001 & 0.45 & 0.0022 \\
\hline hs-CRP, mg/l & 0.23 & 0.0867 & 0.25 & 0.0741 & 0.48 & 0.0008 & 0.38 & 0.0105 \\
\hline HOMA-IR & 0.26 & 0.0498 & 0.26 & 0.0498 & 0.30 & 0.0774 & 0.27 & 0.0774 \\
\hline
\end{tabular}

IAF mass (indicated by IAD) considerably decreased by $20.7 \pm 16.2 \mathrm{~mm}(-32.4 \pm 16.9 \%)$ in boys and $18.4 \pm 12.7 \mathrm{~mm}(-34.3 \pm 18.4 \%)$ in girls $(\mathrm{p}<0.05)$. Concomitant with the decrease in body weight and IAD, marked improvements in blood pressure, serum levels of cholesterol and LDL-cholesterol, $\gamma$ GT, adiponectin as well as in HOMA-IR were observed in both boys and girls (table $1 \mathrm{~b}$ ), being generally more pronounced in boys. In addition, boys showed significant changes in serum levels of TG, HDL-cholesterol, AST and ALT which was not seen in girls.

Patients with the highest baseline IAD (mm) (>75th percentile) showed the largest IAD reduction (\%) as a result of the intervention programme (fig. 1). As expected, relative IAD decrease was highest in patients with the longest therapy duration (fig. 2).

\section{Changes in Metabolic Risk Factors in Relation to Changes in IAD}

The relative decrease in IAD was significantly correlated with the relative decrease in waist circumference and change in BMI-z-score in both genders (table 4). Furthermore, boys showed significant positive correlations of relative change in IAD with relative changes in blood pressure and serum levels of liver enzymes. In girls, significant positive correlations of $\triangle \mathrm{IAD}$ could be found with changes in serum levels of liver enzymes and hs-CRP. Overall, therapy duration had a significant impact on changes in metabolic risk factors in both boys and girls (table 5).

Analysis of the changes in metabolic risk factors in the 3 defined groups $(<25$ th percentile, $>25$ th to $<75$ th percentile, and $>75$ th percentile of $\triangle I A D$ ) showed considerable differences between groups. Between-group comparison analysis using the mean or the median revealed the highest changes in the group with highest relative decrease in IAD. Patients with the highest relative decrease in IAD had the highest change in mean BMI-z-score $(-26.8 \pm 12.6 \%$ (girls) and $-29.1 \pm 10.7 \%$ (boys)) and waist circumference ( $-18.2 \pm 6.0 \%$ (girls) and $-21.1 \pm$ $6.8 \%$ (boys)) compared to patients with lowest relative reduction in IAD (table 6). Although 
Moss et al.: Sonographically Assessed Intra-Abdominal Fat And Cardiometabolic Risk Factors in Adolescents with Extreme Obesity

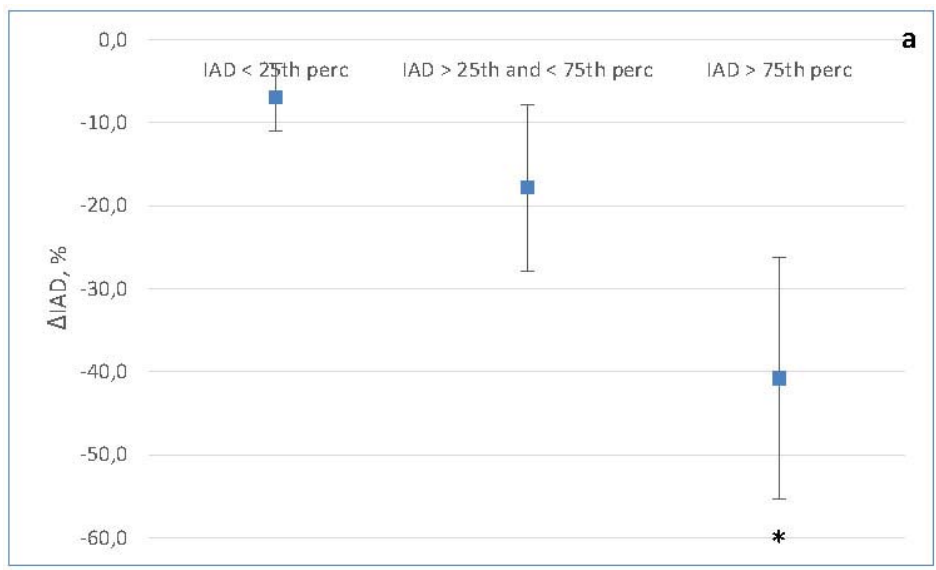

Fig. 1. Relative changes in IAD $(\triangle \mathrm{IAD}, \%)$ in boys (a) and girls (b) with extreme obesity in dependency on level of IAD at baseline examination. IAD at baseline examination ( $\mathrm{mm}$ ) was classified as low (IAD $\leq 25$ th internal percentile), middle (IAD $>25$ th to $<75$ th internal percentile) or high (IAD $\geq 75$ th internal percentile). Data are presented as mean \pm SD. ${ }^{*} \mathrm{p}<$ 0.05 statistically significant between groups (group 1 vs. 3 and 2 vs. 3 boys; group 1 vs. 3 girls).

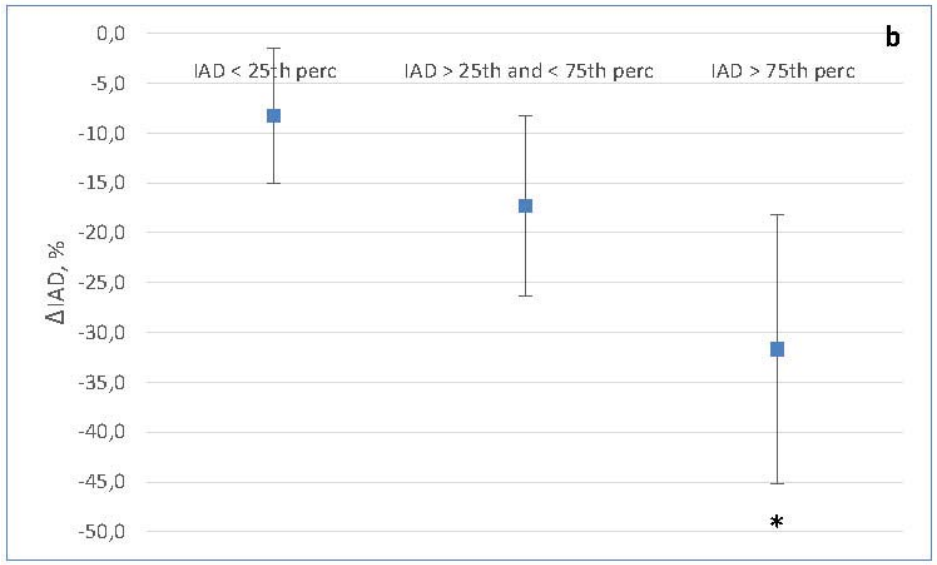

not statistically significant, mean and median relative decreases in serum levels of IL-6 and hs-CRP were found to be highest in the group with the highest relative mean decrease in IAD in both boys and girls (table 6). Only in boys, the highest increase in adiponectin levels corresponded to the highest relative decrease in IAD. Additionally, mean and median changes in blood pressure were found to be highest in boys with the highest changes in IAD. With regard to blood lipids, boys with highest decrease in IAD showed largest relative changes in the median of serum levels of TG, cholesterol, and LDL-cholesterol (table 6). Mean and median relative changes in ALT, AST and $\gamma$ GT were found to be highest in girls with the highest relative decrease in IAD. This was also true for changes in $\gamma \mathrm{GT}$ in boys.

\section{Discussion}

The overall aim of the study has been to assess the clinical significance of IAD measured by ultrasound and of cardiometabolic risk factors in severely obese adolescents and to investigate gender-specific differences. Cross-sectional analysis of the data at baseline showed that IAD is an indicator for an adverse cardiovascular risk factor profile in both genders. The associations between IAD and cardiovascular risk factors however have been more pronounced in boys than in girls. The analysis of the longitudinal data showed that a long-term in-patient treatment programme resulting in a marked mean weight loss lead to a marked decrease in 
Moss et al.: Sonographically Assessed Intra-Abdominal Fat And Cardiometabolic Risk Factors in Adolescents with Extreme Obesity

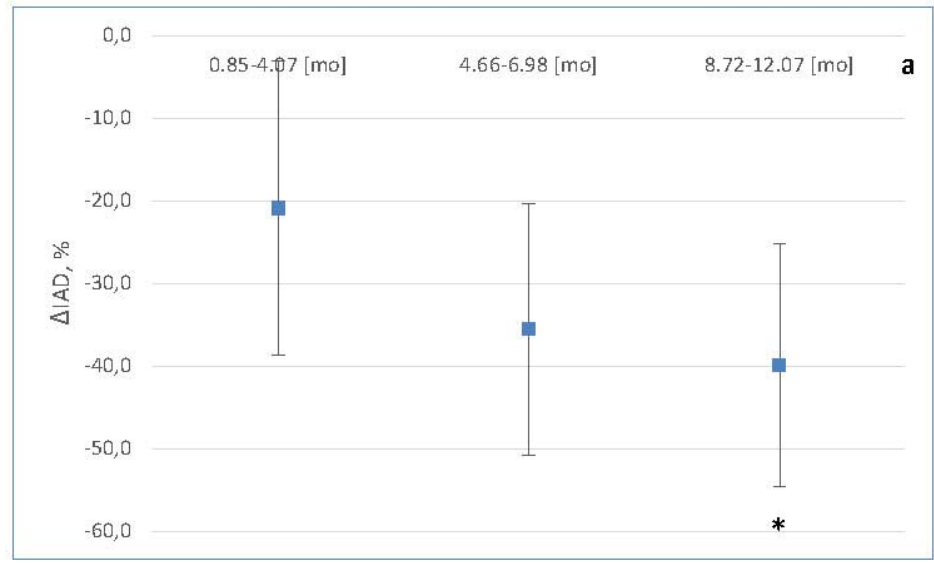

Fig. 2. Relative changes in IAD $(\triangle \mathrm{IAD}, \%)$ in boys (a) and girls (b) with extreme obesity in dependency on therapy duration. Therapy duration (months) was classified as low $(\leq 25$ th internal percentile), middle ( $>25$ th to $<75$ th internal percentile) or high ( $\geq 75$ th internal percentile). Data are presented as mean $\pm \mathrm{SD}$. ${ }^{*} \mathrm{p}<$ 0.05 statistically significant between groups (group 1 vs. 3 boys and girls).

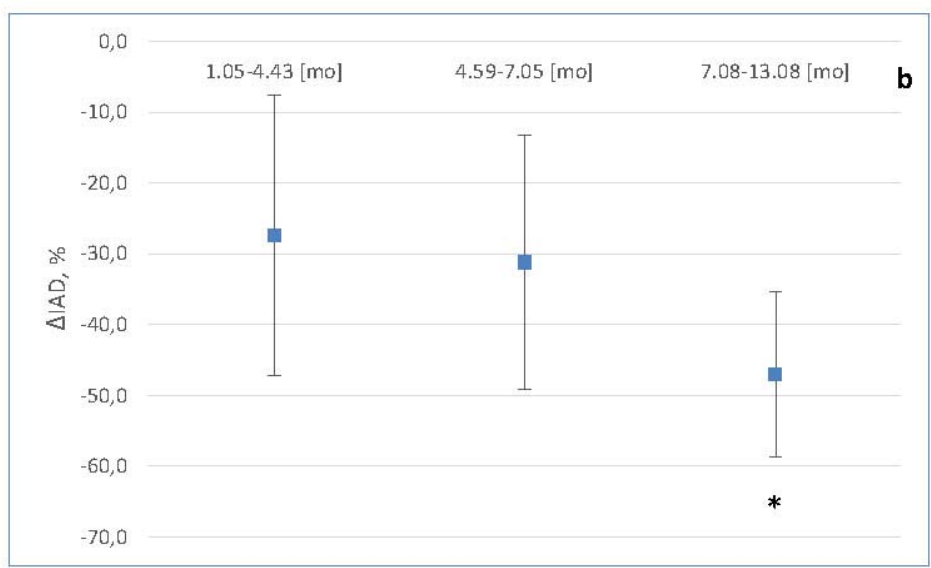

IAF in both genders. The ameliorations of cardiovascular risk factors associated with this decrease were more pronounced in boys than in girls.

For the assessment of IAF CT or MRI were used as gold standard in previous studies, even in children $[44,45,58]$. However, because of their high costs, the radiation exposure (CT) and the limited availability, these methods are not optimal for study purposes. The sonographic estimation of IAF by IAD is a relatively new method, and a good correlation with measurements by CT or MRI for the prediction of abdominal fat mass has been shown both in children and adults [47-50,53]. As formerly reported this sonographic method has high validity, good reproducibility and low intra-observer variation [54]. Our study shows that IAD measured by ultrasound is an easily assessable parameter with clinical significance reflecting the cardiovascular risk factor profile and its changes during weight loss.

\section{Baseline Analyses}

Significant relationships between intra-abdominal fat and several cardiometabolic risk factors have been described in children, adolescents and adults [30,32-34, 37, 59-62]. Within our baseline analysis, we were able to confirm such relationships in adolescents with extreme obesity - however, in a gender-specific manner. Increased IAF has been shown to be associated with an increased risk of cardiovascular morbidity (i.e. hepatic TG content, elevated ALT, insulin resistance and inflammation markers) $[63,64]$. We also could show in our study 
Moss et al.: Sonographically Assessed Intra-Abdominal Fat And Cardiometabolic Risk Factors in Adolescents with Extreme Obesity

Table 4. Cardiometabolic risk factors in relation to baseline IAD

\begin{tabular}{|c|c|c|c|c|c|c|}
\hline \multirow[t]{2}{*}{ Parameter } & \multicolumn{2}{|c|}{$\begin{array}{l}\text { IAD, } m m<25 \text { th internal } \\
\text { percentile }\end{array}$} & \multicolumn{2}{|c|}{$\begin{array}{l}\text { IAD, } \mathrm{mm}>25 \text { th and }<75 \text { th } \\
\text { internal percentile }\end{array}$} & \multicolumn{2}{|c|}{$\begin{array}{l}\text { IAD, } \mathrm{mm}>75 \text { th internal } \\
\text { percentile }\end{array}$} \\
\hline & mean \pm SD & median & mean $\pm \mathrm{SD}$ & median & mean \pm SD & median \\
\hline \multicolumn{7}{|l|}{ Girls } \\
\hline Age, years & $15.0 \pm 2.2$ & 14.0 & $15.2 \pm 2.0$ & 15.0 & $15.2 \pm 2.3$ & 15.5 \\
\hline BMI-z score & $3.2 \pm 0.6$ & 3.2 & $3.4 \pm 0.5$ & 3.3 & $4.0 \pm 0.6$ & 4.0 \\
\hline Waist circumference, $\mathrm{cm}$ & $119.3 \pm 12.0$ & 114.5 & $119.8 \pm 13.7$ & 117.0 & $137.9 \pm 18.7$ & 139.0 \\
\hline RR systolic, mm Hg & $126.1 \pm 11.9$ & 125.0 & $124.0 \pm 10.9$ & 122.5 & $130.1 \pm 14.7$ & 130.0 \\
\hline RR diastolic, mm Hg & $81.6 \pm 6.1$ & 80.0 & $81.3 \pm 9.9$ & 82.5 & $82.5 \pm 9.6$ & 80.0 \\
\hline $\mathrm{TG}, \mathrm{mmol} / \mathrm{l}$ & $1.2 \pm 0.4$ & 1.1 & $1.4 \pm 0.7$ & 1.2 & $1.3 \pm 0.3$ & 1.3 \\
\hline Cholesterol, mmol/l & $4.3 \pm 0.7$ & 4.1 & $4.4 \pm 1.0$ & 4.2 & $4.3 \pm 0.7$ & 4.5 \\
\hline LDL-cholesterol, mmol/l & $2.8 \pm 0.7$ & 2.7 & $2.8 \pm 0.8$ & 2.8 & $2.6 \pm 0.8$ & 2.6 \\
\hline HDL-cholesterol, mmol/l & $1.2 \pm 0.2$ & 1.2 & $1.2 \pm 0.3$ & 1.1 & $1.2 \pm 0.3$ & 1.2 \\
\hline AST, U/l & $23.3 \pm 5.9$ & 23.0 & $27.4 \pm 12.4$ & 23.0 & $21.5 \pm 4.2$ & 22.0 \\
\hline ALT, U/l & $27.1 \pm 8.9$ & 27.0 & $36.0 \pm 26.1$ & 28.5 & $26.0 \pm 9.2$ & 27.0 \\
\hline$\gamma \mathrm{GT}, \mathrm{U} / \mathrm{l}$ & $17.1 \pm 6.2$ & 16.0 & $24.0 \pm 13.3$ & 20.0 & $21.2 \pm 10.6$ & 20.0 \\
\hline Adiponectin, $\mu \mathrm{g} / \mathrm{ml}$ & $6.5 \pm 2.7$ & 5.9 & $6.8 \pm 2.2$ & 6.5 & $6.7 \pm 2.3$ & 6.3 \\
\hline IL-6, pg/ml & $2.9 \pm 2.3$ & 2.2 & $3.5 \pm 2.4$ & 2.9 & $4.3 \pm 2.1$ & 4.3 \\
\hline hs-CRP, mg/l & $3.9 \pm 5.4$ & 1.4 & $4.3 \pm 2.5$ & 3.5 & $8.3 \pm 8.4$ & 5.6 \\
\hline HOMA-IR & $5.1 \pm 2.9$ & 4.2 & $5.3 \pm 2.9$ & 4.8 & $6.4 \pm 3.8$ & 5.4 \\
\hline \multicolumn{7}{|l|}{ Boys } \\
\hline Age, years & $13.8 \pm 1.2$ & 14.0 & $15.5 \pm 2.6$ & 15.5 & $16.6 \pm 3.1$ & 16.0 \\
\hline BMI-z score & $2.8 \pm 0.4$ & 3.0 & $3.2 \pm 0.5$ & 3.2 & $3.3 \pm 0.7$ & 3.3 \\
\hline Waist circumference, $\mathrm{cm}$ & $116.6 \pm 16.9$ & 118.5 & $128.6 \pm 17.2$ & 125.0 & $137.1 \pm 25.9$ & 132.5 \\
\hline RR systolic, mm Hg & $120.1 \pm 9.6$ & 120.0 & $126.0 \pm 10.0$ & 126.3 & $133.4 \pm 10.5$ & 131.3 \\
\hline RR diastolic, mm Hg & $76.4 \pm 6.2$ & 78.3 & $83.3 \pm 9.5$ & 82.5 & $86.8 \pm 6.1$ & 87.3 \\
\hline $\mathrm{TG}, \mathrm{mmol} / \mathrm{l}$ & $1.1 \pm 0.8$ & 0.8 & $1.2 \pm 0.6$ & 1.1 & $1.9 \pm 1.5$ & 1.5 \\
\hline Cholesterol, mmol/l & $4.0 \pm 0.7$ & 4.0 & $4.1 \pm 1.0$ & 4.1 & $4.5 \pm 0.8$ & 4.4 \\
\hline LDL-cholesterol, mmol/l & $2.5 \pm 0.6$ & 2.5 & $2.7 \pm 0.9$ & 2.5 & $2.8 \pm 0.5$ & 2.9 \\
\hline HDL-cholesterol, mmol/l & $1.3 \pm 0.3$ & 1.2 & $1.2 \pm 0.3$ & 1.0 & $1.0 \pm 0.2$ & 0.9 \\
\hline AST, U/l & $29.6 \pm 9.0$ & 29.0 & $33.5 \pm 19.0$ & 28.5 & $30.8 \pm 9.6$ & 26.0 \\
\hline ALT, U/l & $32.4 \pm 17.4$ & 27.0 & $56.6 \pm 49.0$ & 40.5 & $44.8 \pm 22.6$ & 39.0 \\
\hline$\gamma \mathrm{GT}, \mathrm{U} / \mathrm{l}$ & $18.8 \pm 9.0$ & 16.0 & $25.7 \pm 13.6$ & 23.5 & $29.1 \pm 12.3$ & 24.0 \\
\hline Adiponectin, $\mu \mathrm{g} / \mathrm{ml}$ & $7.5 \pm 0.8$ & 7.4 & $6.4 \pm 2.7$ & 5.9 & $5.9 \pm 2.6$ & 5.3 \\
\hline IL-6, pg/ml & $1.8 \pm 0.8$ & 1.7 & $3.6 \pm 2.3$ & 3.0 & $3.6 \pm 1.8$ & 2.7 \\
\hline hs-CRP, mg/l & $1.8 \pm 1.2$ & 1.2 & $5.5 \pm 5.0$ & 3.6 & $7.0 \pm 6.4$ & 4.5 \\
\hline HOMA-IR & $4.7 \pm 1.5$ & 4.6 & $4.1 \pm 1.9$ & 3.5 & $6.6 \pm 3.0$ & 6.1 \\
\hline
\end{tabular}

The analysis was performed after dividing the cohort into 3 subgroups according to initial IAD (group 1 : $<25$ th percentile, group 2: $>25$ th to $<75$ th percentile, group 3: $>75$ th percentile of baseline IAD).

that the higher the level of IAD at baseline, the higher the baseline BMI-z score, waist circumference, blood pressure, HOMA-IR, and IL- 6 and hs-CRP levels in both genders. However, only boys with highest baseline IAD revealed higher levels of TG, cholesterol, LDL-cholesterol, and $\gamma \mathrm{GT}$ as well as lower levels of HDL-cholesterol and adiponectin compared to boys with lower baseline IAD amount. With regard to girls, no comparable trend could be found for blood lipids, liver enzymes and adiponectin.

One possible explanation for these gender-specific observations is that boys had larger baseline amounts of IAD compared to girls. It is well known that body fat distribution is gender-specific, with women having larger stores of subcutaneous fat and men are more likely to have visceral fat $[55,65]$. It has also been postulated that these differences contribute 
Moss et al.: Sonographically Assessed Intra-Abdominal Fat And Cardiometabolic Risk Factors in Adolescents with Extreme Obesity

Table 5. Correlations (crude and adjusted for duration of treatment) between relative changes in measurements of IAD and changes in cardiometabolic risk factors in boys and girls

\begin{tabular}{|c|c|c|c|c|c|c|c|c|}
\hline \multirow[t]{3}{*}{ Parameter } & \multicolumn{8}{|c|}{$\Delta \mathrm{IAD}, \%$} \\
\hline & \multicolumn{4}{|c|}{ girls $(n=59)$} & \multicolumn{4}{|c|}{ boys $(n=48)$} \\
\hline & $\mathrm{r}_{\text {crude }}$ & $\mathrm{p}$ values & $\mathrm{r}_{\mathrm{adj}}{ }^{\mathrm{a}}$ & $\mathrm{p}$ values & $\mathrm{r}_{\text {crude }}$ & $\mathrm{p}$ values & $\mathrm{radj}^{\mathrm{a}}$ & $\mathrm{p}$ values \\
\hline$\Delta$ BMI-z score, $\%$ & 0.34 & 0.0086 & 0.30 & 0.0228 & 0.37 & 0.0097 & 0.23 & 0.1179 \\
\hline$\Delta$ Waist circumference $\%$ & 0.50 & $<0.0001$ & 0.39 & 0.0030 & 0.42 & 0.0013 & 0.31 & 0.0391 \\
\hline$\Delta \mathrm{RR}$ syst, $\%$ & -0.03 & 0.8463 & -0.09 & 0.5041 & 0.32 & 0.0259 & 0.25 & 0.0896 \\
\hline$\Delta \mathrm{RR}$ dias, $\%$ & -0.01 & 0.9637 & -0.10 & 0.4658 & 0.34 & 0.0188 & 0.29 & 0.0442 \\
\hline$\Delta \mathrm{TG}, \%$ & 0.17 & 0.2269 & 0.23 & 0.1002 & 0.16 & 0.3108 & 0.12 & 0.4306 \\
\hline$\Delta$ Cholesterol, $\%$ & 0.16 & 0.2536 & 0.25 & 0.0793 & 0.16 & 0.3001 & 0.10 & 0.5159 \\
\hline$\Delta$ LDL-cholesterol, $\%$ & -0.02 & 0.8958 & 0.07 & 0.6170 & 0.06 & 0.6890 & 0.04 & 0.8160 \\
\hline$\Delta$ HDL-cholesterol, $\%$ & 0.16 & 0.2676 & 0.19 & 0.1740 & -0.03 & 0.8385 & -0.04 & 0.8026 \\
\hline$\Delta \mathrm{AST}, \%$ & 0.35 & 0.0113 & 0.31 & 0.0281 & 0.06 & 0.7100 & -0.02 & 0.8953 \\
\hline$\Delta \mathrm{ALT}, \%$ & 0.26 & 0.0631 & 0.20 & 0.1584 & 0.34 & 0.0281 & 0.23 & 0.1469 \\
\hline$\Delta \gamma \mathrm{GT}, \%$ & 0.37 & 0.0065 & 0.32 & 0.0224 & 0.40 & 0.0073 & 0.35 & 0.0244 \\
\hline$\Delta$ Adiponectin, $\%$ & 0.03 & 0.8536 & 0.01 & 0.9206 & -0.16 & 0.3155 & -0.14 & 0.3728 \\
\hline$\Delta \mathrm{IL}-6, \%$ & 0.24 & 0.0827 & 0.22 & 0.1138 & 0.14 & 0.3628 & 0.27 & 0.0842 \\
\hline$\Delta \mathrm{hs}-\mathrm{CRP}, \%$ & 0.26 & 0.04833 & 0.27 & 0.0475 & 0.16 & 0.3010 & 0.20 & 0.2076 \\
\hline$\Delta$ HOMA-IR, $\%$ & -0.02 & 0.9129 & -0.12 & 0.3980 & 0.20 & 0.2081 & 0.15 & 0.3422 \\
\hline T-duration & -0.41 & 0.0013 & & & -0.39 & 0.0068 & & \\
\hline
\end{tabular}

RR = Riva Rocchi.

$\mathrm{p}<0.05=$ statistically significant.

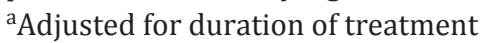

to differences in metabolic, endocrine and health consequences attributable to obesity [66, 67]. However, since in our study the differences in IAD as an estimate of IAF between boys $(58.0 \mathrm{~mm})$ and girls $(51.3 \mathrm{~mm})$ have only been $6.7 \mathrm{~mm}$ in mean, we do not think that the difference in the amount of IAF is the main reason for these gender-specific associations with cardiometabolic risk factors. We postulate hormonally (androgen and/or oestrogen) controlled metabolic processes as being the cause for these differences.

Adipose tissue is an important determinant of low-level chronic inflammatory state as reflected by serum levels of IL-6 and CRP [68]. The association of inflammatory markers with adipose tissue is supported by experimental and clinical evidence [69-71]. As shown in earlier studies, inflammation markers are related to BMI, waist circumference and percent body fat in both genders [72-75]. It has been reported that obese children had about 10 times higher hs-CRP concentrations and higher IL-6 levels than controls [76]. hs-CRP correlated with BMI, waist circumference and percent fat mass [76]. The results of our study in extremely obese adolescents confirmed significant baseline correlations between visceral fat as assessed by ultrasound and inflammation proteins (IL-6, hs-CRP) in both genders.

\section{Longitudinal Analyses}

In general, weight loss is the appropriate approach to reduce the obesity-related health risk. An improvement of cardiovascular risk factors as a result of weight loss during lifestyle intervention has been reported in several studies in children and adolescents $[77,78]$.

The mean weight loss in our long-term treatment study was $-27.1 \pm 16.2 \mathrm{~kg}(-20.1 \pm$ $7.9 \%)$ in boys and $-20.5 \pm 11.5 \mathrm{~kg}(-17.3 \pm 7.1 \%)$ in girls, reducing the mean BMI z-score by $0.8 \pm 0.3$ and $0.7 \pm 0.4$, respectively. This marked weight loss is comparable to the amount of 
Moss et al.: Sonographically Assessed Intra-Abdominal Fat And Cardiometabolic Risk Factors in Adolescents with Extreme Obesity

Table 6. Changes in cardiometabolic risk factors in relation to changes in measurements of IAD

\begin{tabular}{|c|c|c|c|c|c|c|}
\hline \multirow[t]{2}{*}{ Parameter } & \multicolumn{2}{|c|}{$\begin{array}{l}\Delta \mathrm{IAD}, \%<25 \text { th internal } \\
\text { percentile }\end{array}$} & \multicolumn{2}{|c|}{$\begin{array}{l}\triangle \mathrm{IAD}, \%>25 \text { th and }<75 \text { th } \\
\text { internal percentile }\end{array}$} & \multicolumn{2}{|c|}{$\begin{array}{l}\triangle \mathrm{IAD}, \%>75 \text { th internal } \\
\text { percentile }\end{array}$} \\
\hline & mean \pm SD & median & mean \pm SD & Median & mean $\pm \mathrm{SD}$ & median \\
\hline \multicolumn{7}{|l|}{ Girls } \\
\hline$\Delta$ BMI-z score, $\%$ & $-16.7 \pm 13.2$ & -15.1 & $-21.9 \pm 9.0$ & -22.6 & $-26.8 \pm 12.6$ & -24.7 \\
\hline$\Delta$ Waist circumference, $\%$ & $-10.4 \pm 4.4$ & -11.3 & $-13.2 \pm 5.9$ & -12.6 & $-18.2^{*} \pm 6.0$ & -18.7 \\
\hline$\Delta$ RR systolic, $\%$ & $-10.0 \pm 8.8$ & -11.7 & $-7.4 \pm 7.9$ & -7.8 & $-10.6 \pm 8.8$ & -9.5 \\
\hline$\Delta \mathrm{RR}$ diastolic, $\%$ & $-13.4 \pm 11.4$ & -17.0 & $-9.6 \pm 11.6$ & -10.3 & $-10.0 \pm 10.7$ & -9.7 \\
\hline$\Delta \mathrm{TG}, \%$ & $8.6 \pm 35.4$ & 1.1 & $-8.0 \pm 29.3$ & -9.9 & $0.2 \pm 37.6$ & -4.1 \\
\hline$\Delta$ Cholesterol, $\%$ & $-4.4 \pm 16.1$ & -4.4 & $-11.5 \pm 11.9$ & -11.6 & $-6.3 \pm 17.5$ & -9.1 \\
\hline$\Delta$ LDL-cholesterol, $\%$ & $-11.9 \pm 22.2$ & -10.5 & $-17.9 \pm 14.2$ & -20.0 & $-7.1 \pm 20.1$ & -10.0 \\
\hline$\Delta$ HDL-cholesterol, $\%$ & $4.0 \pm 15.1$ & 5.4 & $-2.1 \pm 16.3$ & -5.0 & $0.0 \pm 22.3$ & -7.2 \\
\hline$\Delta \mathrm{AST}, \%$ & $9.7 \pm 39.6$ & 6.9 & $-0.6 \pm 38.6$ & -4.2 & $-16.2 \pm 14.1$ & -14.8 \\
\hline$\Delta \mathrm{ALT}, \%$ & $17.4 \pm 60.9$ & 0.6 & $1.4 \pm 57.9$ & -10.7 & $-18.7 \pm 24.4$ & -20.8 \\
\hline$\Delta \mathrm{yGT}, \%$ & $-2.2 \pm 32.8$ & 2.0 & $-8.2 \pm 34.9$ & -15.4 & $-28.6 \pm 29.8$ & -28.0 \\
\hline$\Delta$ Adiponectin, $\%$ & $20.8 \pm 41.5$ & 22.4 & $27.8 \pm 46.1$ & 11.7 & $23.6 \pm 50.7$ & 13.2 \\
\hline$\Delta \mathrm{IL}-6, \%$ & $-2.0 \pm 54.4$ & -7.5 & $13.8 \pm 88.9$ & -10.8 & $-34.0 \pm 29.6$ & -39.9 \\
\hline$\Delta$ hs-CRP, $\%$ & $-19.2 \pm 59.8$ & -33.6 & $1.3 \pm 117.3$ & -53.6 & $-39.1 \pm 60.7$ & -53.7 \\
\hline$\Delta$ HOMA-IR, \% & $-37.9 \pm 33.8$ & -49.2 & $-25.8 \pm 55.3$ & -35.8 & $-33.6 \pm 27.6$ & -36.8 \\
\hline T-duration, months & $4.9 \pm 1.6$ & 5.6 & $5.8 \pm 2.2$ & 5.9 & $7.3^{*} \pm 2.2$ & 7.1 \\
\hline Age, years & $15.3 \pm 2.3$ & 15.0 & $15.0 \pm 2.2$ & 14.0 & $15.2 \pm 1.8$ & 15.5 \\
\hline \multicolumn{7}{|l|}{ Boys } \\
\hline$\Delta$ BMI-z score, $\%$ & $-17.5 \pm 10.8$ & -14.2 & $-26.9 \pm 12.0$ & -26.4 & $-29.1 \pm 10.7$ & -25.3 \\
\hline$\Delta$ Waist circumference, $\%$ & $-12.5 \pm 5.7$ & -11.9 & $-16.7 \pm 6.6$ & -17.8 & $-21.1 \pm 6.8$ & -19.0 \\
\hline$\Delta \mathrm{RR}$ systolic, $\%$ & $-2.3 \pm 8.0$ & 1.0 & $-7.4 \pm 7.6$ & -5.9 & $-8.8 \pm 8.3$ & -6.9 \\
\hline$\Delta \mathrm{RR}$ diastolic, $\%$ & $-3.6 \pm 11.4$ & -2.4 & $-9.6 \pm 13.0$ & -10.6 & $-15.6 \pm 12.3$ & -13.4 \\
\hline$\Delta \mathrm{TG}, \%$ & $-8.3 \pm 38.6$ & -14.3 & $-17.0 \pm 29.6$ & -19.1 & $-0.1 \pm 103.9$ & -19.6 \\
\hline$\Delta$ Cholesterol, $\%$ & $-14.7 \pm 21.6$ & -7.6 & $-16.2 \pm 10.9$ & -15.6 & $-15.8 \pm 10.7$ & -17.2 \\
\hline$\Delta$ LDL-cholesterol, $\%$ & $-16.9 \pm 13.3$ & -18.8 & $-21.3 \pm 15.2$ & -23.2 & $-19.0 \pm 15.3$ & -23.5 \\
\hline$\Delta$ HDL-cholesterol, $\%$ & $-1.2 \pm 17.2$ & -0.1 & $-1.9 \pm 17.5$ & -6.7 & $-0.6 \pm 21.4$ & -5.9 \\
\hline$\Delta \mathrm{AST}, \%$ & $-11.1 \pm 19.5$ & -15.7 & $-21.7 \pm 21.8$ & -24.1 & $-18.7 \pm 31.1$ & -24.1 \\
\hline$\Delta \mathrm{ALT}, \%$ & $-10.8 \pm 20.8$ & -4.3 & $-41.8^{*} \pm 23.7$ & -43.4 & $-34.6 \pm 33.3$ & -39.3 \\
\hline$\Delta \mathrm{yGT}, \%$ & $-18.0 \pm 27.0$ & -19.9 & $-31.9 \pm 24.8$ & -36.8 & $-37.9 \pm 33.6$ & -48.0 \\
\hline$\Delta$ Adiponectin, $\%$ & $29.9 \pm 41.8$ & 26.7 & $24.7 \pm 32.5$ & 20.7 & $41.9 \pm 44.5$ & 50.9 \\
\hline$\Delta \mathrm{IL}-6, \%$ & $4.9 \pm 67.1$ & -24.3 & $72.6 \pm 233.3$ & -9.0 & $-33.8 \pm 46.3$ & -39.4 \\
\hline$\Delta \mathrm{hs}-\mathrm{CRP}, \%$ & $172.1 \pm 610.8$ & -44.2 & $49.7 \pm 373.8$ & -56.3 & $-60.5 \pm 31.7$ & -70.8 \\
\hline$\Delta$ HOMA-IR, $\%$ & $-8.8 \pm 68.1$ & -32.8 & $-49.4 \pm 32.9$ & -60.8 & $-38.2 \pm 40.2$ & -60.4 \\
\hline T-duration, months & $3.5 \pm 1.9$ & 3.4 & $5.9 \pm 2.3$ & 5.9 & $6.3^{*} \pm 2.3$ & 5.9 \\
\hline Age, years & $14.8 \pm 2.3$ & 14.0 & $15.5 \pm 2.8$ & 15.0 & $15.8 \pm 2.7$ & 15.5 \\
\hline
\end{tabular}

The analysis was performed after dividing the cohort into 3 subgroups according to changes in IAD (group 1: < 25th percentile, group 2: $>25$ th to $<75$ th percentile, group 3: $>75$ th percentile of delta IAD).

$* \mathrm{p}<0.05$ statistically significant between groups.

weight loss achieved by bariatric surgery in extremely obese adolescents [79-81]. Weight loss in the present study resulted in significant reductions in IAD assessed by ultrasound being again clearly higher in boys than in girls. Decreases in IAD as a measure of IAF were associated with an improvement in cardiometabolic risk factors. Interestingly, these improvements of metabolic risk factors showed also gender specifity, with larger benefits in boys than in girls. These results are in line with results of studies in adults, showing that the improvement of cardiovascular risk factors during weight loss is higher in men than in women $[56,57,82]$. 
Moss et al.: Sonographically Assessed Intra-Abdominal Fat And Cardiometabolic Risk Factors in Adolescents with Extreme Obesity

Finally, we could demonstrate that relative changes in cardiometabolic risk factors were correlated with relative changes in IAD assessed by ultrasound. These data suggest that changes in IAD can predict improvements in cardiovascular risk factors in severely obese adolescents. These findings also confirm results of an earlier study of our group, showing that obese adolescents with an abdominal type of body fat distribution benefit more of a weight reduction programme regarding cardiovascular risk factor reduction than patients with a gluteal-femoral type of body fat distribution [83]. To these data, the present study adds measurements of IAF by ultrasound, demonstrating that the IAF is the clinically relevant organ related to these changes.

\section{Strengths and Limitations}

Strengths of this study are the combination of a baseline and follow-up analysis of severely obese adolescents attending a long-term inpatient multimodal obesity programme resulting in a marked amount of weight loss being comparable to that obtained by bariatric surgery. The degree of weight reduction was clinically relevant as demonstrated by an improvement of most cardiometabolic risk factors.

Some potential limitations have to be kept in mind: It must be pointed out that the IAD values assessed via ultrasound depend on the pressure which is applied by the investigator to put the transducer on the abdomen as well as on the patients' respiration. However, the differences in IAD values in this study are likely to be very small because all IAD measurements were conducted by the same experienced investigator.

\section{Conclusions}

The results of the present study show that sonographically assessed IAD is a good indicator for the cardiometabolic risk factor profile in the special risk group of adolescents with extreme obesity. Associations between IAF and the risk factors are more pronounced in boys than in girls. Changes of IAF assessed by ultrasound during marked weight loss are associated with an amelioration of the cardiometabolic risk factor profile, with boys having a greater benefit than girls.

\section{Acknowledgements}

We thank all INSULA patients who participated in this study. We also thank Mrs. Gerlinde Trischler (Department of 2 Internal Medicine II - Cardiology, Medical Clinic Ulm) for the measurement of serum concentrations of cardiometabolic risk factors.

\section{Funding}

This study was supported by grants of German Federal Ministry for Education and Research within the German Competence Network on Obesity (BMBF, project funding reference number: 01GI1120A). Further support was given by 'Stiftung Juvenile Adipositas'. 
Moss et al.: Sonographically Assessed Intra-Abdominal Fat And Cardiometabolic Risk Factors in Adolescents with Extreme Obesity

\section{Authorships Section}

Conceived and designed the study: AM, MW, WS. Performed the clinical measurements: WS, AS. Analysed the data: AM, SB. Wrote the first draft of the manuscript: AM. Contributed to the writing of the manuscript: AM, MW, SB, KS, WS, AS, WK. Agree with final manuscript and conclusions: AM, MW, SB, KS, WS, AS, WK.

\section{Disclosure Statement}

The authors have nothing to disclose.

\section{References}

$>1$ Olds T, Maher C, Zumin S, Peneau S, Lioret S, Castetbon K, Bellisle, de Wilde J, Hohepa M, Maddison R, Lissner L, Sjoberg A, Zimmermann M, Aeberli I, Ogden C, Flegal K, Summerbell C: Evidence that the prevalence of childhood overweight is plateauing: data from nine countries. Int J Pediatr Obes 2011;6:342-360.

2 Wabitsch M, Moss A, Kromeyer-Hauschild K: Unexpected plateauing of childhood obesity rates in developed countries. BMC Med 2014;12:17.

-3 Ogden CL, Carroll MD, Curtin LR, Lamb MM, Flegal KM: Prevalence of high body mass index in US children and adolescents, 2007-2008. JAMA 2010;303:242-249.

-4 Claire Wang Y, Gortmaker SL, Taveras EM: Trends and racial/ethnic disparities in severe obesity among US children and adolescents, 1976-2006. Int J Pediatr Obes 2011;6:12-20.

5 Must A, Jacques PF, Dallal GE, Bajema CJ, Dietz WH: Long-term morbidity and mortality of overweight adolescents. A follow-up of the Harvard Growth Study of 1922 to 1935. N Engl J Med 1992;327:1350-1355.

7 Mossberg HO: 40-year follow-up of overweight children. Lancet 1989;2:491-493.

7 Freedman DS, Mei Z, Srinivasan SR, Berenson GS, Dietz WH: Cardiovascular risk factors and excess adiposity among overweight children and adolescents: the Bogalusa Heart Study. J Pediatr 2007;150:12-17. e2.

-8 Calcaterra V, Klersy C, Muratori T, Telli S, Caramagna C, Scaglia F, Cisternino M, Larizza D: Prevalence of metabolic syndrome (MS) in children and adolescents with varying degrees of obesity. Clin Endocrinol 2008;68: 868-872.

-9 Gidding SS, Nehgme R, Heise C, Muscar C, Linton A, Hassink S: Severe obesity associated with cardiovascular deconditioning, high prevalence of cardiovascular risk factors, diabetes mellitus/hyperinsulinemia, and respiratory compromise. J Pediatr 2004;144:766-769.

-10 Ice CL, Murphy E, Cottrell L, Neal WA: Morbidly obese diagnosis as an indicator of cardiovascular disease risk in children: results from the CARDIAC Project. Int J Pediatr Obes 2011;6:113-119.

11 Kelly AS, Metzig AM, Schwarzenberg SJ, Norris AL, Fox CK, Steinberger J: Hyperleptinemia and hypoadiponectinemia in extreme pediatric obesity. Metab Syndr Relat Disord 2012;10:123-127.

12 Norris AL, Steinberger J, Steffen LM, Metzig AM, Schwarzenberg SJ, Kelly AS: Circulating oxidized LDL and inflammation in extreme pediatric obesity. Obesity (Silver Spring) 2011;19:1415-1419.

13 Henry RR, Gumbiner B: Benefits and limitations of very-low-calorie diet therapy in obese NIDDM. Diabetes Care 1991; 14:802-823.

14 Hamilton CC, Geil PB, Anderson JW: Management of obesity in diabetes mellitus. Diabetes Educ 1992;18:407410.

15 Olefsky JM, Kolterman OG, Scarlett JA: Insulin action and resistance in obesity and noninsulin-dependent type II diabetes mellitus. Am J Physiol 1982;243:E15-30.

16 Reaven GM: Banting lecture 1988. Role of insulin resistance in human disease. Diabetes 1988;37:1595-1607.

-17 Wabitsch M, Hauner H, Hertrampf M, Muche R, Hay B, Mayer H, Kratzer W, Debatin KM, Heinze E: Type II diabetes mellitus and impaired glucose regulation in Caucasian children and adolescents with obesity living in Germany. Int J Obes Relat Metab Disord 2004;28:307-313.

-18 Ebbeling CB, Pawlak DB, Ludwig DS: Childhood obesity: public-health crisis, common sense cure. Lancet 2002; 360:473-482.

19 Freedman DS, Srinivasan SR, Harsha DW, Webber LS, Berenson GS: Relation of body fat patterning to lipid and lipoprotein concentrations in children and adolescents: the Bogalusa Heart Study. Am J Clin Nutr 1989;50: 930-939.

20 Horswill CA, Zipf WB: Elevated blood pressure in obese children: influence of gender, age, weight and serum insulin levels. Int J Obes 1991;15:453-459.

-21 I'Allemand D, Wiegand S, Reinehr T, Müller J, Wabitsch M, Widhalm K, Holl R; APV-Study Group:Cardiovascular risk in 26,008 European overweight children as established by a multicenter database. Obesity (Silver Spring) 2008;16:1672-1679.

-22 Reinehr T, Andler W, Denzer C, Siegried W, Mayer H, Wabitsch M: Cardiovascular risk factors in overweight German children and adolescents: relation to gender, age and degree of overweight. Nutr Metab Cardiovasc Dis 2005;15:181-187. 
Moss et al.: Sonographically Assessed Intra-Abdominal Fat And Cardiometabolic Risk

Factors in Adolescents with Extreme Obesity

23 Shear CL, Freedman DS, Burke GL, Harsha DW, Berenson GS: Body fat patterning and blood pressure in children and young adults. The Bogalusa Heart Study. Hypertension 1987; 9:236-244.

24 Zwiauer KF, Pakosta R, Müller T, Widhalm K: Cardiovascular risk factors in obese children in relation to weight and body fat distribution. J Am Coll Nutr 1992;11(suppl):41S-50S.

25 Whitaker RC, Wright JA, Pepe MS, Seidel KD, Dietz WH: Predicting obesity in young adulthood from childhood and parental obesity. N Engl J Med 1997;337:869-873.

26 Despres JP: Abdominal obesity as important component of insulin-resistance syndrome. Nutrition 1993;9: 452-459.

27 Wabitsch M, Hauner H, Heinze E, Muche R, Bockmann A, Parthon W, Mayer H, Teller W: Body-fat distribution and changes in the atherogenic risk-factor profile in obese adolescent girls during weight reduction. Am J Clin Nutr 1994;60:54-60.

28 Lapidus L, Bengtsson C, Larsson B, Pennert K, Rybo E, Sjostrom L: Distribution of adipose tissue and risk of cardiovascular disease and death: a 12 year follow up of participants in the population study of women in Gothenburg, Sweden. Br Med J (Clin Res Ed) 1984;289:1257-1261.

29 Larsson B, Svardsudd K, Welin L, Wilhelmsen L, Bjorntorp P, Tibblin G: Abdominal adipose tissue distribution, obesity, and risk of cardiovascular disease and death: 13 year follow up of participants in the study of men born in 1913. Br Med J (Clin Res Ed) 1984;288:1401-1404.

-30 Freedman DS, Srinivasan SR, Burke GL, Shear CL, Smoak CG, Harsha DW, Webber LS, Berenson GS: Relation of body fat distribution to hyperinsulinemia in children and adolescents: the Bogalusa Heart Study. Am J Clin Nutr 1987;46:403-410.

-31 Maffeis C, Banzato C, Brambilla P, Cerutti F, Corciulo N, Cuccarolo G, Di Pietro M, Franzese A, Gennari M, Balsamo A, Grugni G, Iughetti L, Del Giudice EM, Petri A, Trada M, Yiannakou P; Obesity Study Group of the Italian Society of Pediatric Endocrinology and Diabetology: Insulin resistance is a risk factor for high blood pressure regardless of body size and fat distribution in obese children. Nutr Metab Cardiovasc Dis 2010;20: 266-273.

-32 Baumgartner RN, Siervogel RM, Chumlea WC, Roche AF: Associations between plasma lipoprotein cholesterols, adiposity and adipose tissue distribution during adolescence. Int J Obes 1989;13:31-41.

-33 Zwiauer K, Widhalm K, Kerbl B: Relationship between body fat distribution and blood lipids in obese adolescents. Int J Obes 1990;14:271-277.

-34 Gillum RF: The association of body fat distribution with hypertension, hypertensive heart disease, coronary heart disease, diabetes and cardiovascular risk factors in men and women aged 18-79 years. J Chronic Dis 1987;40:421-428.

-35 Fujioka S, Matsuzawa Y, Tokunaga K, Tarui S: Contribution of intra-abdominal fat accumulation to the impairment of glucose and lipid metabolism in human obesity. Metabolism 1987;36:54-59.

-36 von Eyben FE, Mouritsen E, Holm J, Montvilas P, Dimcevski G, Suciu G, Helleberg I, Kristensen L, von Eyben R: Intra-abdominal obesity and metabolic risk factors: a study of young adults. Int J Obes Relat Metab Disord 2003;27:941-949.

-37 Kim SK, Kim HJ, Hur KY, Choi SH, Ahn CW, Lim SK, Kim KR, Lee HC, Huh KB, Cha BS: Visceral fat thickness measured by ultrasonography can estimate not only visceral obesity but also risks of cardiovascular and metabolic diseases. Am J Clin Nutr 2004;79:593-599.

38 Gower BA, Nagy TR, Goran MI: Visceral fat, insulin sensitivity, and lipids in prepubertal children. Diabetes 1999;48:1515-1521.

39 Owens S, Gutin B, Ferguson M, Allison J, Karp W, Le NA: Visceral adipose tissue and cardiovascular risk factors in obese children. J Pediatr 1998;133:41-45.

40 Brambilla P, Manzoni P, Sironi S, Simone P, Del Maschio A, di Natale B, Chiumello G: Peripheral and abdominal adiposity in childhood obesity. Int J Obes Relat Metab Disord 1994;18:795-800.

41 Kim JA, Park HS: Association of abdominal fat distribution and cardiometabolic risk factors among obese Korean adolescents. Diabetes Metab 2008;34:126-130.

42 Tamura A, Mori T, Hara Y, Komiyama A: Preperitoneal fat thickness in childhood obesity: association with serum insulin concentration. Pediatr Int 2000;42:155-159.

43 Caprio S, Hyman LD, Limb C, McCarthy S, Lange R, Sherwin RS, Shulman G, Tamborlane WV: Central adiposity and its metabolic correlates in obese adolescent girls. Am J Physiol 1995;269:E118-126.

44 Fox K, Peters D, Armstrong N, Sharpe P, Bell M: Abdominal fat deposition in 11-year-old children. Int J Obes Relat Metab Disord 1993;17:11-16.

45 Goran MI, Kaskoun M, Shuman WP: Intra-abdominal adipose tissue in young children. Int J Obes Relat Metab Disord 1995;19:279-283.

-46 de Ridder CM, Thijssen JH, Bruning PF, Van den Brande JL, Zonderland ML, Erich WB: Body fat mass, body fat distribution, and pubertal development: a longitudinal study of physical and hormonal sexual maturation of girls. J Clin Endocrinol Metab 1992;75:442-446.

$\checkmark 47$ Armellini F, Zamboni M, Rigo L, Todesco T, Bergamo-Andreis IA, Procacci C, Bosello O: The contribution of sonography to the measurement of intra-abdominal fat. J Clin Ultrasound 1990;18:563-567.

-48 Ribeiro-Filho FF, Faria AN, Azjen S, Zanella MT, Ferreira SR: Methods of estimation of visceral fat: advantages of ultrasonography. Obes Res 2003;11:1488-1494.

49 Stolk RP, Wink O, Zelissen PM, Meijer R, van Gils AP, Grobbee DE: Validity and reproducibility of ultrasonography for the measurement of intra-abdominal adipose tissue. Int J Obes Relat Metab Disord 2001;25:1346-1351. 
Moss et al.: Sonographically Assessed Intra-Abdominal Fat And Cardiometabolic Risk

Factors in Adolescents with Extreme Obesity

50 Tornaghi G, Raiteri R, Pozzato C, Rispoli A, Bramani M, Cipolat M, Craveri A: Anthropometric or ultrasonic measurements in assessment of visceral fat? A comparative study. Int J Obes Relat Metab Disord 1994;18: 771-775.

-51 Kromeyer-Hauschild K, Wabitsch M, Kunze D, Gellert F., Geiß HC, Hesse V, Von Hippel A, Jaeger U, Johnsen D, Korte W, Menner K, Müller G, Müller JM, Niemann-Pilatus A, Remer T, Schaefer F, Zabransky S, Zellner K, Ziegler A, Hebebrand J: Perzentile für den Body-mass-Index für das Kindes- und Jugendalter unter Heranziehung verschiedener deutscher Stichproben. Monatsschr Kinderheilk 2001;149:807-818.

52 von Schnurbein J, Klenk J, Galm C, Berg S, Gottmann P, Steinacker JM, Kratzer W, Brandstetter S, Wartha O, Peter R, Weiland S, Wabitsch M: Reference values and early determinants of intra-abdominal fat mass in primary school children. Horm Res Paediatr 2011;75:412-422.

53 Ferrozzi F, Zuccoli G, Tognini G, Castriota-Scanderbeg A, Bacchini E, Bernasconi S, Campani R: An assessment of abdominal fatty tissue distribution in obese children. A comparison between echography and computed tomography (in Italian). Radiol Med 1999;98:490-494.

-54 Ribeiro-Filho FF, Faria AN, Kohlmann O Jr, Ajzen S, Ribeiro AB, Zanella MT, Ferreira SR: Ultrasonography for the evaluation of visceral fat and cardiovascular risk. Hypertension 2001;38:713-717.

55 Power ML, Schulkin J: Sex differences in fat storage, fat metabolism, and the health risks from obesity: possible evolutionary origins. Br J Nutr 2008;99:931-940.

56 Wing RR, Jeffery RW: Effect of modest weight loss on changes in cardiovascular risk factors: are there differences between men and women or between weight loss and maintenance? Int J Obes Relat Metab Disord 1995; 19:67-73.

57 Wirth A, Steinmetz B: Gender differences in changes in subcutaneous and intra-abdominal fat during weight reduction: an ultrasound study. Obes Res 1998;6:393-399.

58 de Ridder CM, de Boer RW, Seidell JC, Nieuwenhoff CM, Jeneson JA, Bakker CJ, Zonderland ML, Erich WB: Body fat distribution in pubertal girls quantified by magnetic resonance imaging. Int J Obes Relat Metab Disord 1992;16:443-449.

59 Bjorntorp P: The associations between obesity, adipose tissue distribution and disease. Acta Med Scand Suppl 1988;723:121-134.

60 Seidell JC, Cigolini M, Charzewska J, Ellsinger BM, Di Biase G, Bjorntorp P, Hautvast JG, Contaldo F, Szostak V, Scuro LA: Indicators of fat distribution, serum lipids, and blood pressure in European women born in 1948 the European Fat Distribution Study. Am J Epidemiol 1989;130:53-65.

-61 Seidell JC, Cigolini M, Deslypere JP, Charzewska J, Ellsinger BM, Cruz A: Body fat distribution in relation to serum lipids and blood pressure in 38-year-old European men: the European fat distribution study. Atherosclerosis 1991;86:251-260.

62 Leenen R, van der Kooy K, Seidell JC, Deurenberg P: Visceral fat accumulation measured by magnetic resonance imaging in relation to serum lipids in obese men and women. Atherosclerosis 1992;94:171-181.

-63 Burgert TS, Taksali SE, Dziura J, Goodman TR, Yeckel CW, Papademetris X, Constable RT, Weiss R, Tamborlane WV, Savoye M, Seyal AA, Caprio S: Alanine aminotransferase levels and fatty liver in childhood obesity: associations with insulin resistance, adiponectin, and visceral fat. J Clin Endocrinol Metab 2006;91:4287-4294.

-64 van der Poorten D, Milner KL, Hui J, Hodge A, Trenell MI, Kench JG, London R, Peduto T, Chisholm DJ, George J: Visceral fat: a key mediator of steatohepatitis in metabolic liver disease. Hepatology. 2008;48:449-457.

65 Lemieux S, Prud'homme D, Bouchard C, Tremblay A, Despres JP: Sex differences in the relation of visceral adipose tissue accumulation to total body fatness. Am J Clin Nutr 1993;58:463-467.

66 Racette SB, Evans EM, Weiss EP, Hagberg JM, Holloszy JO: Abdominal adiposity is a stronger predictor of insulin resistance than fitness among 50-95 year olds. Diabetes Care 2006;29:673-678.

-67 Karelis AD, St-Pierre DH, Conus F, Rabasa-Lhoret R, Poehlman ET: Metabolic and body composition factors in subgroups of obesity: what do we know? J Clin Endocrinol Metab 2004;89:2569-2575.

-68 Yudkin JS, Stehouwer CD, Emeis JJ, Coppack SW: C-reactive protein in healthy subjects: associations with obesity, insulin resistance, and endothelial dysfunction: a potential role for cytokines originating from adipose tissue? Arterioscler Thromb Vasc Biol 1999;19:972-978.

-69 Fried SK, Bunkin DA, Greenberg AS:. Omental and subcutaneous adipose tissues of obese subjects release interleukin-6: depot difference and regulation by glucocorticoid. J Clin Endocrinol Metab 1998;83:847-850.

70 Park HS, Park JY, Yu R: Relationship of obesity and visceral adiposity with serum concentrations of CRP, TNFalpha and IL-6. Diabetes Res Clin Pract 2005;69:29-35.

71 Rexrode KM, Pradhan A, Manson JE, Buring JE, Ridker PM: Relationship of total and abdominal adiposity with CRP and IL-6 in women. Ann Epidemiol 2003;13:674-682.

72 Panagiotakos DB, Pitsavos C, Yannakoulia M, Chrysohoou C, Stefanadis C: The implication of obesity and central fat on markers of chronic inflammation: the ATTICA study. Atherosclerosis 2005;183:308-315.

73 Hak AE, Stehouwer CD, Bots ML, Polderman KH, Schalkwijk CG, Westendorp IC, Hofman A, Witteman JC: Associations of $\mathrm{C}$-reactive protein with measures of obesity, insulin resistance, and subclinical atherosclerosis in healthy, middle-aged women. Arterioscler Thromb Vasc Biol 1999;19:1986-1991.

-74 Lemieux I, Pascot A, Prud'homme D, Almeras N, Bogaty P, Nadeau A, Bergeron J, Despres JP: Elevated C-reactive protein: another component of the atherothrombotic profile of abdominal obesity. Arterioscler Thromb Vasc Biol 2001;21:961-967. 
75 Yamada S, Gotoh T, Nakashima Y, Kayaba K, Ishikawa S, Nago N, Nakamura Y, Itoh Y, Kajii E: Distribution of serum C-reactive protein and its association with atherosclerotic risk factors in a Japanese population: Jichi Medical School Cohort Study. Am J Epidemiol 2001;153:1183-1190.

-76 Mauras N, Delgiorno C, Kollman C, Bird K, Morgan M, Sweeten S, Balagopal P, Damaso L: Obesity without established comorbidities of the metabolic syndrome is associated with a proinflammatory and prothrombotic state, even before the onset of puberty in children. J Clin Endocrinol Metab 2010;95:1060-1068.

-77 Reinehr T, de Sousa G, Toschke AM, Andler W: Long-term follow-up of cardiovascular disease risk factors in children after an obesity intervention. Am J Clin Nutr 2006;84:490-496.

78 Reinehr T, Kleber M, Toschke AM: Lifestyle intervention in obese children is associated with a decrease of the metabolic syndrome prevalence. Atherosclerosis 2009;207:174-180.

79 Brandt ML, Harmon CM, Helmrath MA, Inge TH, McKay SV, Michalsky MP: Morbid obesity in pediatric diabetes mellitus: surgical options and outcomes. Nat Rev Endocrinol 2010;6:637-645.

80 Inge TH, Zeller MH, Lawson ML, Daniels SR: A critical appraisal of evidence supporting a bariatric surgical approach to weight management for adolescents. J Pediatr 2005;147:10-19.

81 Treadwell JR, Sun F, Schoelles K: Systematic review and meta-analysis of bariatric surgery for pediatric obesity. Ann Surg 2008;248:763-776.

82 LaRosa JC: Lipids and cardiovascular disease: do the findings and therapy apply equally to men and women? Womens Health Issues1992;2:102-111; discussion 111-113.

83 Wabitsch M, Hauner H, Bockmann A, Parthon W, Mayer H, Teller W: The relationship between body fat distribution and weight loss in obese adolescent girls. Int J Obes Relat Metab Disord 1992;16:905-911. 